\title{
Solar Dryer for Large/Medium Scale Ripening and Drying of Dates; A Case Study of Dates Growing Area of Pakistan
}

\author{
Saeeda Sultana ${ }^{a}$, Syed Hussain ${ }^{b}$, Muhammad Farooq*c and Muhammad Ehsan ${ }^{\text {d }}$ \\ ${ }^{\mathrm{a}}$ Goverment College for Women, Muzaffargarh, Pakistan \\ ${ }^{b}$ Pakistan Council of Renewable Energy Technologies, 25, H-9 Islamabad, Pakistan \\ ${ }^{\mathrm{c}}$ Directorate of Quality Enhancement, Bahauddin Zakariya University, Multan, Pakistan \\ ${ }^{\mathrm{d} P a k i s t a n}$ Council for Scientific and Industrial Research, Lahore, Pakistan
}

(received July 13, 2017; revised January 22, 2019; accepted January 24, 2019)

\begin{abstract}
This study describe the design features and performance of the unglazed transpired solar dryer for large and medium scale drying of Dates in the Dates growing area of Pakistan. The dryer has the designed capacity to dry $500 \mathrm{Kg}$ of Dates from Khalaal ( $70 \%$ humidity) to Tamar ( $25 \%$ humidity), at 55 ${ }^{\circ} \mathrm{C} \pm 5{ }^{\circ} \mathrm{C}$ in 72 continuous hours using biomass furnace as an auxiliary heat source and it covers approximately $256 \mathrm{~m}^{2}$ areas. This is the ideal humidity condition to store Dates for one year without any further degradation. In traditional open sunshine the huge quantity of Dates are dried in over $150 \mathrm{~h}$ hours and requires hectare of area to spread the Dates. Moreover, the quality of Dates in the open sunshine is affected badly due to two main reasons. Firstly, the heavy dust in the area that sticks the Dates during the drying process makes them unable to eat. Secondly, the Monsoon rains in the months of July and August also destroys Dates placed in the open areas for drying. Dera Ismail (D.I.) Khan, a remote district of Khyber Pakhtoon Khawa province of Pakistan, was selected to study the performance of Dates dryer, where solar insolation is $700-750 \mathrm{~W} / \mathrm{m}^{2}$ in the months of July and August. The Dates were dried continuously and during off sunshine hours biomass auxiliary source was used. This solar dryer, containing eight trolleys and each trolley is loaded with twelve trays, is the first in Pakistan to dry a large amount of Dates. Moreover, the unglazed transpired dryer is designed in such a way that it can withstand the dusty atmosphere of D.I. Khan and also protect the Dates from dust and rainy water during the drying period. The design does not have any adverse effect on the quality of dried Dates. In D.I. Khan around 350 days are sunny per year and solar thermal technology is economically feasible compared to other conventional energy resources with a payback period of 3 and 7.5 years compared to un-subsided and subsided cost of Natural Gas respectively. The Natural Gas is the cheapest conventional energy source in Pakistan. But solar thermal technology is yet not popular source of energy in the area due to lack of information, fear of initial capital cost and weak government policies for renewable energies. This study also incorporates the recommendations to overcome these issues regarding Solar Thermal Technology, PACS Number: 44.40.+a, 89.30.Cc, 84.60.h, 89.30.-g.
\end{abstract}

Keywords: thermal radiation, solar power, direct energy conversion, energy resources

\section{Introduction}

Agriculture forms are the base of Pakistan's economy, which produces large quantities of grains, fruits and vegetables. Around $70 \%$ of the 177 million population of Pakistan is employed in agriculture sector and it is the major source of income and foreign exchange for the country Qazi (2011). Pakistan is blessed with a tropical climate in Dates growing areas, ideal for production of Dates, and it is fourth in the world in Dates production. Here the annual production of Dates is about 535,000 tones which are partially exported and mostly it is locally consumed. There are more than 300 varieties of Dates in Pakistan. Out of these large number

*Author for correspondence; E-mail: mfarooq67@hotmail.com of varieties, Dhakki of Dera Ismail Khan, Begam Jangi of Balochistan and Aseel of Sindh are the varieties which have high international demand due to their exotic taste. Lack of post harvesting processing facilities make these valuable varieties which are highly demand in European and Asian countries, unable to get its worth in the export market (The Express Tribune Pakistan, 2011).

Pakistan, being a developing country, mainly depends on traditional harvesting and post harvesting techniques. As a result lower quality of agriculture products are produced and formers have to face economic losses. The modernization of post harvesting techniques using sustainable and low cost solar technologies offers 
opportunities to stimulate economic growth and this is aim of this study. But due to the inadequate post harvest care, it is estimated that about $20-30$ percent of the produce is wasted and the remaining product is of lower quality for human consumption. The traditionally harvested Dates contain dust and insect infection and their quality is so poor that it does not meet the criteria of International market to export and earn foreign exchange. Due to the substandard quality, the Dates farmers are unable to get reasonable price in the local market as a result of living standard of the poor people in remote areas is affected. If solar dryers are used to remove excess moisture from the Dates before storage, then their quality will be enhanced and insect infestation will be minimized. Similarly, large quantities of excess Dates, now being wasted could be solar dried in a controlled environment and would be available to export and for use during off-season. Solar dryer technology is well developed and can be used for bulk drying in a controlled environment. Solar dryers involve a nominal initial cost but they produce better looking, better tasting, and more nutritious foods Boubekri et al. (2009). The food value of Dates and their marketability is enhanced. The dryers make the drying process much faster, safer and efficient than traditional sun drying techniques.

In Pakistan Dates processing by solar dryer is under exploited. Perishable farm produce are wasted or sold at throw-away prices during the peak seasons due to inadequate post harvest storage facilities and lack of effective processing or preservation techniques. On the other side marketing problems for Dates in Pakistan is same as it is in other Date producing countries. These include irregular production, poor choice of cultivars, crop damage caused by insect pests and plant pathogens, poor crop quality due to traditional harvesting and drying methods, lack of post harvest technology, insufficient organization of marketing process, and intensive market competition of imported Dates Nejjar (1999). The ripening season for Dates starts with the rise in summer temperature in June and August is the peak production period. Unfortunately the Monsoon and dust stormy seasons also falls within these months of the year. This is real bottleneck for this crop to harvest and store. This solar dryer has been designed to address the above mentioned environmental issues and dry Dates at required temperature and humidity.

The traditional methods are still popular for ripening/ curing the fruits and vegetables for obvious reasons of high cost and unavailability of conventional energy and lack information about emerging solar drying technologies. The Dates at the Dong stage are spread on mats and exposed to sun in open air and time for complete ripening and drying of the Dates in the Pakistan is very long due to dusty atmosphere. Normally it takes more than one and half week to dry Dates in the open sun as at night the temperature of the Dates drops and it takes time to reach optimal temperature of drying next day provided there is no rain in that period. The quality of traditionally sun-dried product under dusty condition becomes very poor and non-uniform with low yield. Due to persistent rain and stormy condition a large amount of the harvested Dates become moldy, fermented, and dusty and damaged by bird and insects. The growers become disheartened and consequently the rate of further cultivation and propagation of Dates product is being impaired badly. Due to the waste of crop, people have trend to make Chuharas (cut dried Dates) and export to neighbouring countries like India at throw away prices to save post harvest loses in the production of Tamar (complete) Dates.

The conventional energy sources like electricity, natural gas and hydrocarbons are in acute shortage of supply in Pakistan and very expensive to be used for drying fruits and vegetables. Today, Pakistan is facing more than $5000 \mathrm{MW}$ electricity shortfall and about 900 MMcfd shortfalls in the Natural Gas (WAPDA, 2011) data. Both the shortfalls are overcome through load management plans on daily basis. On the other side, the cost of conventional energy in Pakistan like electricity and natural gas is unaffordable for farmers to dry Dates. Further more, farmers are socially reluctant to adopt new harvesting technologies like solar drying due the fear of higher technological cost. Fortunately, Pakistan is blessed with plenty of sunshine in Dates and vegetable growing areas. The solar intensity in the under study area varies from $700 \mathrm{~W} / \mathrm{m}^{2}$ to $750 \mathrm{~W} / \mathrm{m}^{2}$ for about 8 hours per day in the Dates growing season and the same have been confirmed in this study as well Sukhera et al. (1986). This energy is abundant, free of cost and requires simple technology to dry Dates. For this study solar energy and biomass, both are abundant and freely available in the area, have been used to continuously dry Dates in shortest possible time by using minimum space to easily handle bulk amount of Dates. This solar dryer design is very simple to copy and fabricate using locally available material and semiskilled manpower. 
In this study the attempts to understand the socioeconomic importance of Dates ripening and drying in Pakistan to formulate appropriate interventions to improve the sector. This is being done by using freely available solar energy, biomass energy, simple dryer design with optimum performance and socially acceptable to adopt and reproduce these dryers. The main beneficiaries will include Dates producers who will focus on their production to meet the national and international market demand of better quality dried Dates. Processors/farmers will have better access to technologies, processing techniques and to market demand information. Researchers and other service providers will be able to focus on factors that are of economic importance to the fruit-drying sector, issued rose during the drying process and latest developments in solar thermal technologies.

A large medium size solar dryer for average farmers in Pakistan has been designed, fabricated and tested for drying of Dates keeping in view the simplicity of fabrication and use with optimal results. The design allows the use of minimum space for Dates to spread and uses locally available resources like sun and biomass to dry Dates in continuous short interval. Solar energy as a clean and cheep energy source is proved to be an alternatives of conventional energy especially in sunbelt countries like Pakistan for solar drying. This typical dryer uses solar and biomass energy for continuous heating and electricity for exhaust fans to remove humidity from the chambers. The results are very encouraging and this design of solar dryer is being tested in other part of the country to ensure its suitability against dust, rain and minor variation in solar intensity for all parts of the Dates growing areas of Pakistan.

\section{Material and Methods}

Drying techniques and methodology. This type of dryers use solar and biomass energy to heat the air in the drying chamber to flows over the Dates. The relative humidity of the heated air in the chamber decreases and is capable to hold more moisture form the Dates. This moisture is captured from the Dates by the dry air and the same is vented through exhaust chamber. This process continues till the desired amount of moisture is maintained in the Dates. It is worth to mention that the required temperature must be maintained for drying Dates failing to which the quality of dry Dates would be affected. In this particular case $55^{\circ} \mathrm{C} \pm 5^{\circ} \mathrm{C}$ chamber temperature is essential for drying from Rutab to Tamar.
For the ease of users, the temperature and humidity of other fruits and vegetables has also been mentioned in the Table. 1 [http://www.fao.org/docrep/t0681E/ t0681e05.htm].

With the passage of time, the actual amount of moisture evaporated per unit of time decreases. Initially, the moisture from the outer surfaces of the Dates evapourates till dried. The moisture from the inner surface of the Dates has to move to the top surface and it takes time which slows the drying process. During the drying of inner surface, overheating on the upper surface may occur due to the slower rate of moisture evaporation. If the temperature is more than $50{ }^{\circ} \mathrm{C} \pm 5^{\circ} \mathrm{C}$ in this period, the Dates quality would be badly affected. To avoid overheating during this inner surface drying of the Dates, the rate of airflows through exhaust fan was controlled to maintain required temperature. However, Khalal stage Dates is very temperature sensitive and to ripe Khalal Dates to Rutab by heating, the chamber temperature was maintained to $55^{\circ} \mathrm{C} \pm 5^{\circ} \mathrm{C}$ for $10 \mathrm{~h}$ in a day and no biomass auxiliary was used at night to avoid overheating and this was repeated for two consecutive days and data has been recorded for sunny period of $20 \mathrm{~h}$. After the careful removal of moisture from the most outer surface, the continuous drying started using auxiliary biomass till complete drying.

For this study, the most abundant Dates growing area like D. I. Khan was selected to investigate the performance of the dryers in real conditions. The

Table 1. Maximum permissible temperature for drying agricultural produce and their initial and final moisture contents.

\begin{tabular}{llll}
\hline \hline Produce & \multicolumn{2}{l}{ Moisture content $(\%)$} & $\begin{array}{l}\text { Max. permissible } \\
\text { temperature }\left({ }^{\circ} \mathrm{C}\right)\end{array}$ \\
\hline Dates & Initial & Final \\
Chilies & 70 & 25 & $50-55$ \\
Onions & 80 & 5 & 65 \\
Potatoes & 80 & 4 & 55 \\
Apple & 75 & 13 & 75 \\
Apricots & 80 & 24 & 70 \\
Green peas & 80 & 18 & 65 \\
Green beans & 70 & 5 & 65 \\
Cauliflower & 80 & 6 & 75 \\
Cabbage & 80 & 4 & 65 \\
Tomatoes & 96 & 10 & 55 \\
Brinjal & 95 & 6 & 60 \\
Peaches & 85 & 18 & 60 \\
Grapes & 80 & $15-20$ & 65 \\
\hline \hline
\end{tabular}


Table 2. Dates developmental stages \& their characteristics

\begin{tabular}{|c|c|c|c|}
\hline Stages & Detail of Dates & $\begin{array}{l}\text { Required } \\
\text { Temperature for } \\
\text { drying \& } \\
\text { Humidity }\end{array}$ & Picture \\
\hline Khalaal & $\begin{array}{l}\text { Yellowish colour, } \\
19-25 \text { weeks } \\
\text { Moisture } 60 \%\end{array}$ & $\begin{array}{l}\mathrm{T}: 50-55^{\circ} \mathrm{C} \\
\text { For ripening } \\
\text { of Dates }\end{array}$ & \\
\hline Rutab & $\begin{array}{l}\text { Golden brown, } \\
\text { Sugar partially inverted, } \\
\text { juicy and soft tissue, } \\
26-28 \text { week, } \\
\text { Moisture } 35 \%\end{array}$ & $\begin{array}{l}\mathrm{T}: 50-55^{\circ} \mathrm{C} \\
\text { For } \\
\text { drying of Dates }\end{array}$ & \\
\hline Tamar & $\begin{array}{l}\text { Dark Brown } \\
\text { Complete Dates } \\
29 \text { week } \\
\text { Moisture 23-25\% }\end{array}$ & $\begin{array}{l}\mathrm{T}: 50-55^{\circ} \mathrm{C} \\
\text { Complete Dried } \\
\text { Dates }\end{array}$ & \\
\hline
\end{tabular}

temperature and humidity required to dry the Dates is given in the Table. 2 and this paper describe the study of Khalal Dates drying to Tamar Dates. Thermohygrometers were installed in two chambers to monitor the temperature and humidity at one hour interval. The ambient temperature and humidity were also recorded at the same interval. The intensity of the light was recorded with the help of illuminometer and it remained $700-750 \mathrm{~W} / \mathrm{m}^{2}$ in the months of July and August but it has not been presented in hourly data in the paper.

The community participation has been ensured and local farmers were trained to take over the dryer after completion of the study. The feedbacks form the farmers were also taken and addressed in the paper. Therefore, the social and geographical issues have been discussed in this paper along with recommendations to make solar drying technology popular in Dates growing areas.

Dryer design. Active solar dryers using exhaust fan to move the hot air from collector to the drying chamber has been used. In the developing countries flat plat solar energy collector are used in dryers for its lesser complication in design and operation. These kind of solar collectors with metal sheet unglazed absorbers had collector efficiencies up to $30 \%$ and reached temperature rise of only about $50{ }^{\circ} \mathrm{C}$ (at ambient 35-40 ${ }^{\circ} \mathrm{C}$ ). While, glass cover absorbers have improved efficiencies to $60 \%$ and dryer temperature rises to 60 ${ }^{\circ} \mathrm{C}$ (at ambient $35-40{ }^{\circ} \mathrm{C}$ ) studied by Jensen et al. (2001).
However, further addition of the glazing and insulation just increases the cost of the collector for solar dryer.

The unglazed transpired collector (UTC) developed for this study comprises of commercial black-coated perforated plate. Ambient air is forced into the plenum through the holes in the plate as shown in Fig. 1. It is worth to mention that the UTC does not require any glazing and insulation while, reduced the cost of the collector significantly. Collector efficiency has been noted between 50 to $70 \%$ at a temperature between 50 to $60{ }^{\circ} \mathrm{C}$ (at ambient $35-40{ }^{\circ} \mathrm{C}$ ). Studies by Kutscher et al. have highlighted the performance of the UTC as a low-cost alternative to glazed flat plate solar collectors (Kutscher et al., 1993 and 1991). Limited investigation by Meer and Machlin concluded that the UTC would be an appropriate technology for drying applications Meer and Machlin (2001). Under the conditions, the UTC dryer seems to be appropriate and economically viable option to select for Dates dryers. Therefore, the design of this type of collectors is presented here along with the problems faced during the real study.

The specifications of the dryer are given below: Actual collector area $=60$ square meters and ( 20 collector having 3 square-meters each); Perforation diameter $=$ $2.0 \mathrm{~mm}$; Plenum depth $=10 \mathrm{~cm}$; Electrical power required $=$ Six fans of 40 Watts each

The hybrid UTC dryer was designed with the biomass furnace as an auxiliary heat source. This ensures the continuous operation of the dryer during clouds season at the night. The hot air from the collector enter into the dryer chamber which passes through the trays and takes the moisture from the dates being dried. The

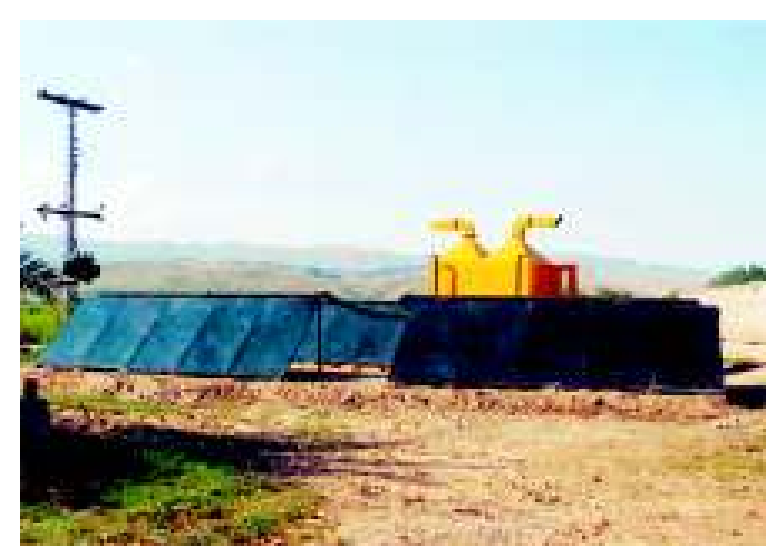

Fig. 1. Picture of the complete solar dryer. 
exhaust vent located on top of the drying chamber expels the moisture in the air by the use of exhaust fans. The biomass furnace ignites the hot air through the primary air inlet during off sunshine period. Convective heat transfer from the fins and outer surface of the heat exchanger to the air entering the drying chamber raises the effective temperature within the chamber. The heated air circulates through the drying chamber and evaporates the moisture from the Dates on the drying trays and exits through the exhaust vent as described earlier. The pipe type heat exchanger built-into the primary air inlet of the furnace heats the delivery system and combustion rate of the furnace is regulated by the amount of air flow into the furnace. The Fig. 1-3 show the pictures of the complete dryer, trays and Dates in Khalaal and Tamar stages respectively.

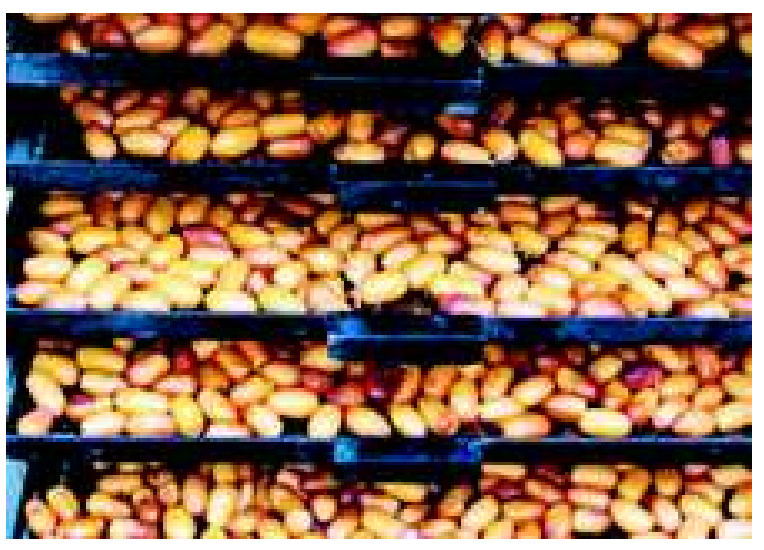

Fig. 2. Picture of the trays of the solar dryer (Khalaal stage).

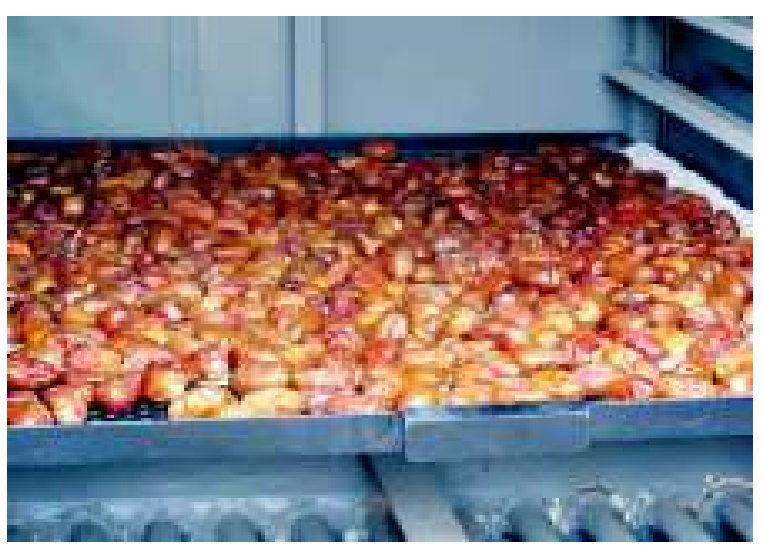

Fig. 3. Picture of the dried (Tamar) Dates.
The dryer was design to dry $500 \mathrm{Kg}$ of Dates in one run by reducing humidity from $70 \%$ to $25 \%$ The relevant equation to determine the mass of water lost from the Dates is (Gatea, 2011).

$\mathrm{MW}=\mathrm{M}_{\mathrm{C}}\left[\left(\mathrm{W}_{\mathrm{I}}-\mathrm{W}_{\mathrm{F}}\right) /\left(100-\mathrm{W}_{\mathrm{F}}\right)\right]$

where:

$\mathrm{W}_{\mathrm{I}}=$ the initial moisture content; $\mathrm{W}_{\mathrm{F}}=$ the final moisture content; $\mathrm{M}_{\mathrm{C}}=$ the initial mass of the crop; $\mathrm{M}_{\mathrm{W}}=$ the mass of the moisture evapourated and therefore is 500 $[(70-25) /(100-25)]=300 \mathrm{Kg}$. It is assumed that each $\mathrm{Kg}$ of water requires $2.5 \mathrm{MJ}$ of heat for its removal, then the total heat needed is $300 \times 2.5=750 \mathrm{MJ}$.

\section{Results and Discussion}

To prove that the design is appropriate and capable to dry the Dates at $50-60{ }^{\circ} \mathrm{C}$ within $72 \mathrm{~h}$ the ambient temperature and humidity were recorded along with humidity and temperatures of, Chamber-1 and Chamber2. In this study we selected Khalaal (humidity 70\%), Dates to dry them to Tamar shapes (humidity 25\%). However, Dates can also be picked from the Dates plants in the shapes of Rutab shapes (humidity 35\%) to dry them to Tamar.

Chamber temperature. The Dates were dried to Tamar in continuous $72 \mathrm{~h}$ and the first reading in the data was taken at 8.00 a.m. The data consist of the ambient temperature, temperatures of Chamber 1 and Chamber2. The ambient temperature starts rising at 8.00 a.m. and reaches it's maximum at $38^{\circ} \mathrm{C}$ at $2.00 \mathrm{pm}$ and then decreases to $24{ }^{\circ} \mathrm{C}$ at $2.00 \mathrm{am}$. To supply uninterrupted heat to Dates, the auxiliary heat was supplied to the drier chambers after $6.00 \mathrm{pm}$ using biomass energy. It can be seen from Fig. 4 that the temperature in both the chambers remained similar and constant at around 52$56{ }^{\circ} \mathrm{C}$ during the entire $72 \mathrm{~h}$ of drying process except few short interval Peaks. It shows that both the chambers are receiving same amount of energy and it is the reflection of successful designing. Three peaks in chambers temperature were observed (Fig. 4) due to the plenty of sunshine at $2.00 \mathrm{pm}$ and rise of ambient temperature that resulted in lower thermal heat losses. However, these peaks are of short duration and did not exceed the upper control limit of chamber temperature that might adversely affect the drying quality of the Dates. However, this can be avoided by covering few of the solar collectors of the dryer but we have ignored 
it for the sake of actual data this time. From Fig. 4 it is observed that the design of the dryer with exhaust fans is appropriate to keep the chamber temperature constant at $55^{\circ} \mathrm{C}$ to $60^{\circ} \mathrm{C}$ during the entire $72 \mathrm{~h}$.

Chamber humidity. The ambient humidity of the chamber changes along with the ambient temperature in day and night cycle. The humidity is maximum at mid night (2.00 a.m.) and decreases to minimum at mid day time (2.00 p.m.). From Fig. 5, it can be seen that humidity of the chamber increases during initial $12 \mathrm{~h}$ due to the evapouration of water particles from the upper surface of the Dates in Khalal shape. However, after the saturated evaporation, the Dates starts drying and the humidity decrease constantly with the passage of time. After 45-50 h the humidity of Dates reaches to $35 \%$ and the Dates are in Rutab shapes and are ready for consumption as fresh Dates. It is worth to mention that in Pakistan Dates are conventionally picked in Rutab form as well from the Dates plants. Therefore, within $25 \mathrm{~h}$ these Dates can be completely dried to Tamar shapes. This design is effective, consistent and produces quality dried dated in specified minimum time.

Economic considerations. The major source of energy in Pakistan is Natural Gas which is locally produced and comparatively cheaper than other energy sources like electricity, oil or coal. It has major share of $44 \%$ in the energy mix of Pakistan (OGDCL Annual Report, 2012). However, it is not available in remote areas of the country for use. In these days Pakistan is facing

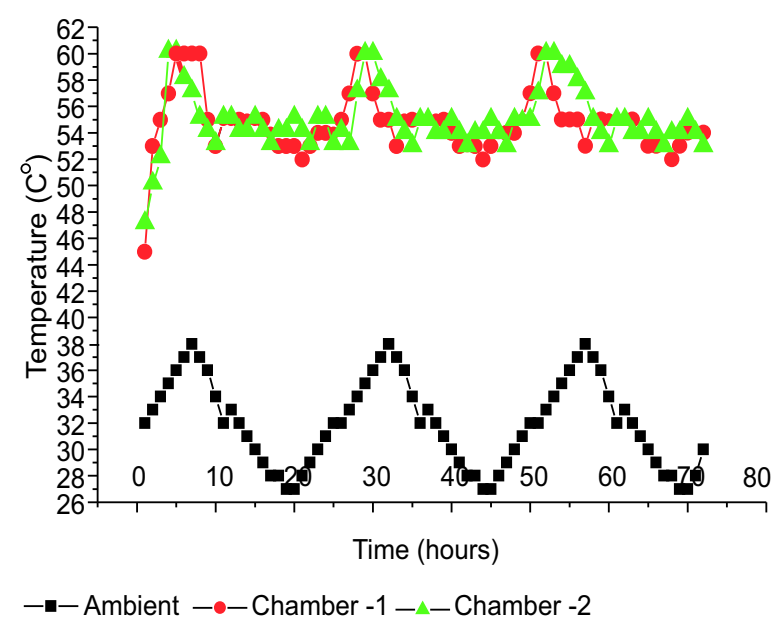

Fig. 4. Temperature profile of dryer chamber and ambient temperature.

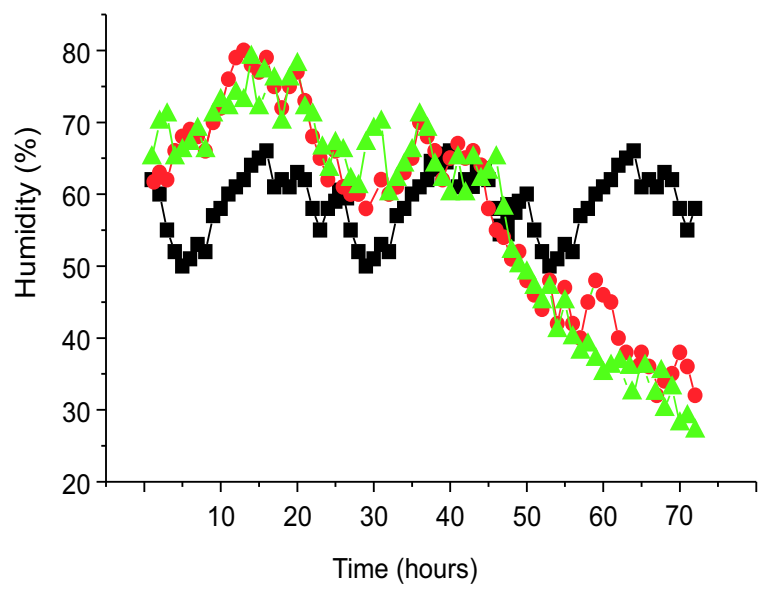

Fig. 5. Humidity profiles of dryer chamber and ambient humidity.

acute shortage of natural gas due to its lower cost and heavy consumption in electricity generation and industrial utilization like fertilizers. Natural gas being a cheapest energy source has been compared with solar dryer cost to verify that solar thermal energy is economically feasible in Pakistan. The natural gas heating value over here is $40 \mathrm{MJ} / \mathrm{m}^{3}$ with burning efficiency of $60 \%$.

The perforated collectors have an average efficiency of $50 \%$ and average annual solar insolation in D. I. Khan Pakistan is $5.7 \mathrm{kWh} / \mathrm{m}^{2} \mathrm{~d}$; and it is available for 350 days per year. Then from a surface area of $60 \mathrm{~m}^{2}$ it should deliver $5.7 \times 0.4 \times 60 \times 350 \times 3.6 \mathrm{MJ}=172368$ MJ.

The natural gas heating delivered from the Burner would be $172368 /(40 \times 0.60)=7182$ per $^{3}$

Current natural gas domestic subsided price in Pakistan; Rs $=190$ per MMBTU

Cost of the gas is Rs $=32756$

Current natural gas price in Pakistan; Rs $=463$ per MMBTU

Cost of the gas is Rs $=79636$

Cost of the dryer Rs $=250,000$

Payback period compared with subsided gas 7.6 years Payback period compared with un-subsided gas 3.1 years.

It is worth to mention that the current natural gas prices have been used for calculation of Payback period. However, during last two years natural gas prices have been increased more than $70 \%$. Keeping in view the above trend of price rise in natural gas, this will further reduce the Payback period. The normal life of solar 
dryer is around 25 years. Therefore, solar dryer is economically feasible in Pakistan in comparison to all sources of energy, as we have compared solar drying with cheapest source of energy i.e. natural gas even if, it is available in area. In case of non availability of the natural gas the cost of transportation would further increase the cost of conventional energy.

Reasons for unacceptability of solar energy in Pakistan. Though solar thermal technology is economically viable option in Pakistan but still it is not socio-economically widely acceptable for number of following reasons which were observed during this study.

- A large population of Pakistan, especially farmers, is illiterate and they are unaware of solar thermal echnology, its use, feasibility and benefits. Unfortunately, solar thermal technology is normally compared with photovoltaic energy which is unjustified.

- Solar energy is abundant in Pakistan but the expertise are lacking for system sizing in solar thermal energy technologies to perfectly meet the needs of the farmers/customers. As a result few unsuccessful stories by untrained technician defamed the solar thermal energy technologies.

- In very near past, natural gas, electricity and petroleum products were subsided in Pakistan for farmers and renewable energy was not on the priority list of Government of Pakistan. But now the above mentioned subsidies have been withdrawn and farmers are looking for alternative options. However, it will take time for solar thermal technology to penetrate in the market as communication medium in remote areas are not very effective compared to the cities.

- Public sector organization like Pakistan Council of Renewable Energy Technology and Alternative Energy Development Board, responsible for promotion and dissemination of renewable technologies in the country are not efficient and also do not have the capacity to reach remote areas thoroughly. The linkages among various such organization and other stakeholders like farmers and local governments are very weak Shah et al. (2011). As a result the dissemination of solar thermal technologies like dryers is limited to few places only.

- The policies of government of Pakistan in the past were not encouraging for promotion of renewable energy technologies. However, recent sever energy crises of Pakistan forced policy makers to promote renewable technologies especially solar thermal technologies as an alternative source of energy to reduce the energy shortfall in the country. As a result Government of Pakistan showed commitment to promote solar thermal technologies through tax exemptions and establishment of pilot projects in solar thermal technologies and this project is one such example.

- Socially farmers are reluctant to leave traditional techniques of fruit and vegetable dryings. A campaign to familiarize solar technologies through electronic and print media with the cooperation of local government is essential for its success.

\section{Conclusions}

This solar dryers design is successful for medium and large size Dates growers and it is cost effective to dry Dates in sunny climates for preservation of entire next year. The quality of the Dates dried in controlled environment was very good for human consumption. This dryer is capable of drying other fruit and vegetables with slight modification in air flow rate. This study also envisages that the services of only trained technician for system sizing for solar dryers must be used to avoid perception of technology failure. The close coordination among organization disseminating solar thermal technologies and its users is essential. Subsidized policies for renewable energy technologies should be adopted for at least ten years to ensure consistency in subsidy policies. A crash awareness program in solar thermal technologies should be launched in local languages which are understandable to the farmers.

Conflict of Interest. The authors declare no conflict of interest.

\section{References}

Boubekri, A., Benmoussa, H., Mennouche, D. 2009. Solar drying kinetics of date palm fruits assuming a step-wise air temperature change, Journal of Engineering Science and Technology, 4: 292-304.

Gatea, A.A. 2011. Design and construction of a solar drying system, a cylindrical section and analysis of the performance of the thermal drying system, African Journal of Agricultural Research, 6: 343351.

Jensen, S.O., Kristensen, E.F., Forman, T. 2001. Test of a Solar Crop Dryer, $1^{\text {st }} \mathrm{Ed}, \mathrm{p} .4$, Danish Institute of Agricultural Technology, Denmark.

Kutscher, C.F., Christensen, C., Barker, G. 1993. Unglazed transpired solar collectors: heat loss 
theory, ASME Journal of Solar Energy Engineering, 115: $182-188$.

Kutscher, C.F., Christensen, C., Barker, G. 1991. Unglazed transpired solar collectors: an analytical model and test results, Proceedings of ISES Solar World Congress, Vol. 2, Part 1, pp. 1245-1250, Pergamon Press, Colorado, USA.

Meer, H.R., Machlin, A. 2001. Potential applications of thermal solar energy in the Egyptian food processing industry, USAID Project Report, pp. 37

Nejjar, M. 1999. Les problèmes de commercialisation des dattes au Maroc, In: Agroeconomie Des Oasis, Ferry, M. Bedrani, S., Greiner, D. (Ed), pp. 95102, GRIDAO, Montpellier Codex 1, France.

OGDCL. 2012. Annual Report 2011, Oil and Gas Development Company Limited, pp1-111 Jinnah
Avenue, Blue Area, Islamabad, Pakistan

Qazi, S. Annual Report. 2011, Ministry of Population Welfare, Government of Pakistan, Islamabad, Pakistan.

Shah, A.A., Rashidi, R.S., Bhutto, A., Shah, A. 2011. The real life scenario for diffusion of renewable energy technologies (RETs) in Pakistan - Lessons learned through the pilot field study under physical community, Renewable and Sustainable Energy Reviews, 15: 2210-2213.

Sukhera, M.B., Pashsa, M.A.R., Naveed, M.S. 1986. Solar radiation over Pakistan-comparison of measured and predicted data, Solar and Wind Technology, 3: 219-221.

Water and Power Development Authority of Pakistan, (WAPDA) Data June 2011 (www.wapda.org.pk) 